\title{
Investigation of the Relationship between Retinal Nerve Fiber Layer Thickness and Mild Cognitive Impairment
}

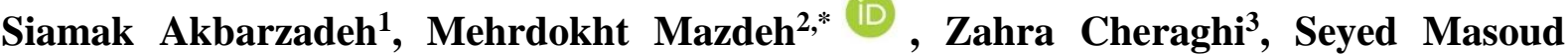 \\ Seyedan ${ }^{4}$ \\ ${ }^{I}$ Associate Professor, Department of Ophthalmology, School of Medicine, Hamadan University of Medical Sciences, \\ Hamadan, Iran \\ 2 Professor, Department of Neurology, School of Medicine, Hamadan University of Medical Sciences, Hamadan, Iran \\ ${ }^{3}$ Assistant Professor, Department of Epidemiology, School of Health, Hamadan University of Medical Sciences, Hamadan, \\ Iran \\ ${ }^{4}$ General Practitioner, Hamadan University of Medical Sciences, Hamadan, Iran \\ * Corresponding Author: Mehrdokht Mazdeh, Department of Neurology, School of Medicine, Hamadan University of Medical \\ Sciences, Hamadan, Iran. Email: mehrdokhtmazdeh@yahoo.com
}

Received: 28.07 .2019

Accepted: 17.11 .2019

How to Cite this Article: Akbarzadeh S, Mazdeh $M$, Cheraghi Z, Seyedan SM Investigation of the Relationship between Retinal Nerve Fiber Layer Thickness and Mild Cognitive Impairment. Avicenna J Clin Med. 2019; 26(3): 158165. DOI: $10.29252 /$ ajcm. 26 3.158

\section{Abstract}

Background and Objective: This study investigated the difference between patients with mild cognitive impairment and healthy controls using Optical Coherence Tomography (OCT) regarding Retinal Nerve Fiber Layer (RNFL) thickness.

Materials and Methods: In total, 20 patients with mild cognitive impairment and 20 healthy controls were subjected to neurological examination in this case-control study. The examinations included Minimal Mental State Examination test, comprehensive examination of the eye, and OCT using SPECTRALIS ${ }^{\circledR}$. The data were analyzed to evaluate the thickness of RFNL through descriptive and analytical statistics. Both eyes were selected for analysis, and the patients with mild cognitive impairment were compared with the healthy controls regarding the RFNL thickness.

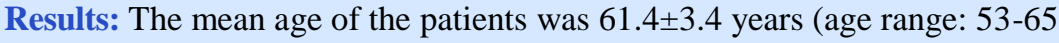
years), and the mean RNFL thickness in patients was $100 \pm 10.1 \mu \mathrm{m}$. Moreover, the mean values of RNFL thickness in the lower, upper, nasal, and temporal quadrants were $128 \pm 18.9,119 \pm 12.2,87 \pm 14.06$, and $68 \pm 10.3$ $\mu \mathrm{m}$, respectively. There was no difference between females $(99 \pm 13.2)$ and males $(103 \pm 5.6)$ regarding the RNFL thickness. In addition, no significant difference was observed between the male and female age groups in terms of the RNFL thickness. Additionally, there was no significant difference between the patients $(100 \pm 10.1)$ and control group (104 \pm 8.7$)$ regarding the RNFL thickness. The chance of developing mild cognitive impairment is increased by 1.45 times with increasing age. It should be noted that this relationship was statistically significant $(\mathrm{P}<0.001)$.

Conclusion: The results of this study indicate that patients with mild cognitive impairment had reduced RNFL thickness, compared to healthy controls. However, since this difference was not significant, it cannot be regarded as a proper approach for diagnosis and follow up of the patients.

Keywords: Mild Cognitive Impairment, Minimal Mental State Examination, Retinal Nerve Fiber Layer Thickness 


\title{
بررسى ارتباط ضخامت لايه فيبر هاى عصبى شبكيه با بيمارى اختلال شناختى خفيف
}

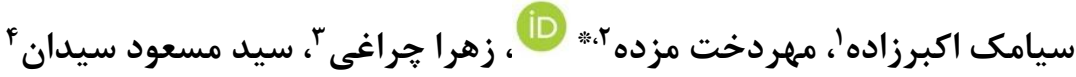 \\ 'دانشيار، گروه حشميزشكى، دانشكده يزشكى، دانشكاه علوم يزشكى همدان، همدان، ايران

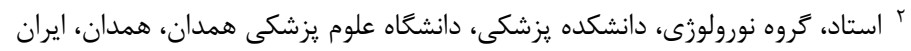

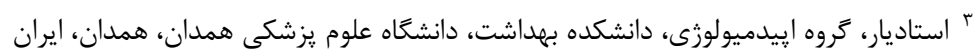

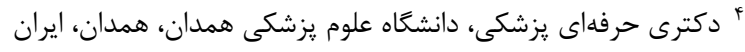

* نويسنده مسئول: مهردخت مزده، گروه نورولوزى، دانشكده يزشكى، دانشكاه علوم يزشكى همدان، همدان، ايران.

ايميل: mehrdokhtmazdeh@yahoo.com

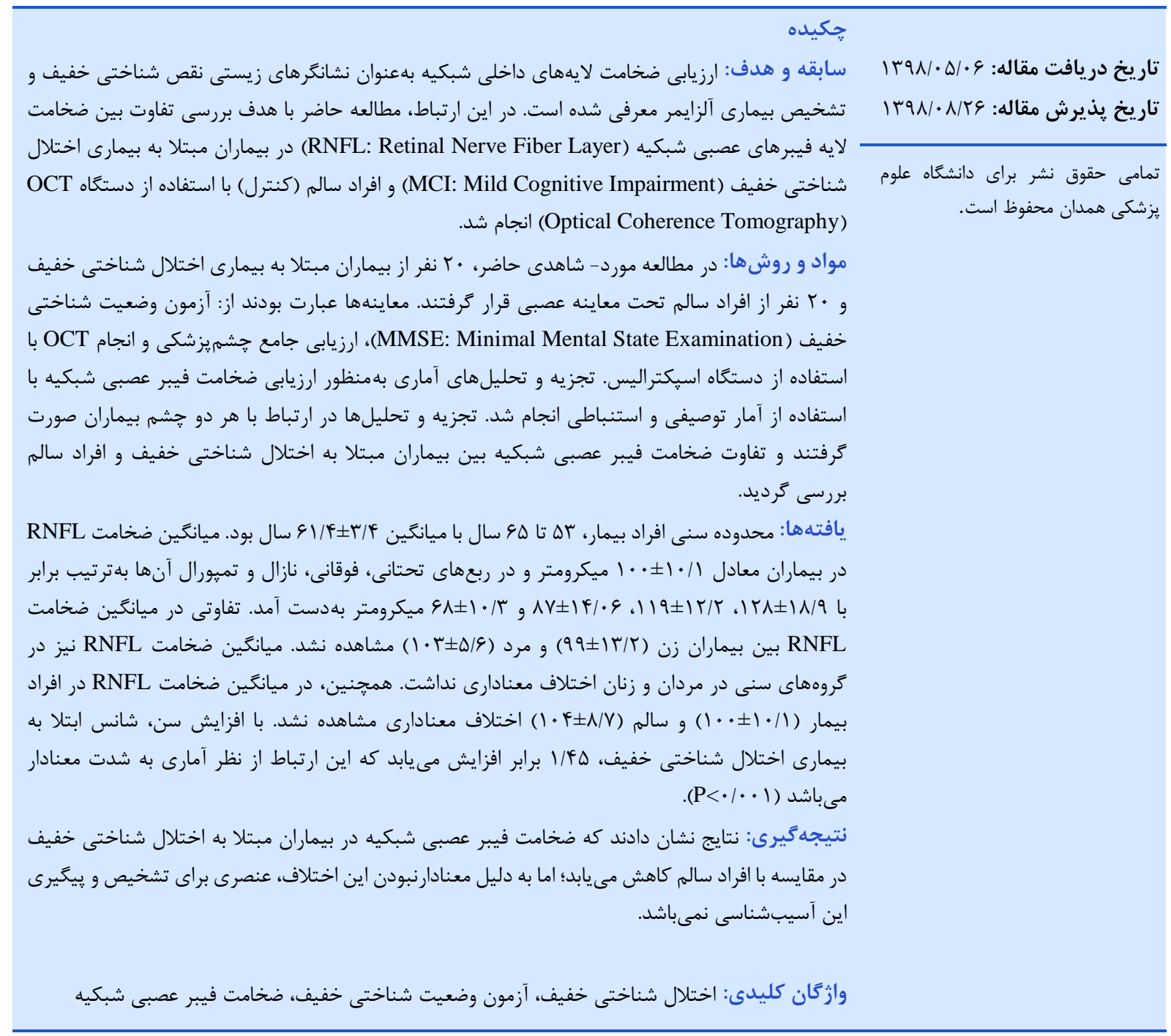

مقلدمه

نقصـان عملكردهاى شناختى، بيشتر از تغييرات طبيعى وابسته

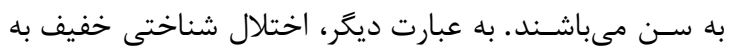

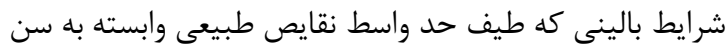

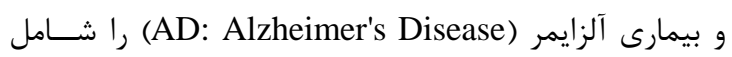

اختلال شـــــاختى خفيف (MCI) يك مرحله ميانى بين زوال شناختى طبيعى مورد انتظار در دوره پييرى و مراحل اوليه

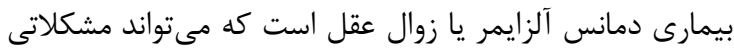

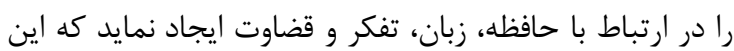




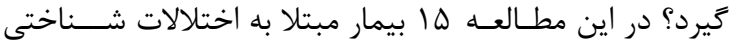

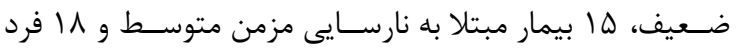

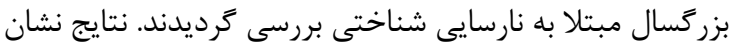

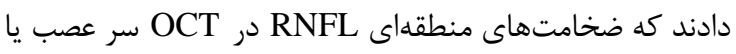
عصسبى بين گروهها تفاوتى ندارند. با اين وجود، تجزيه و و تحليل

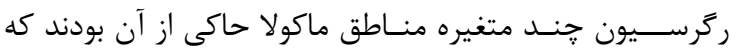

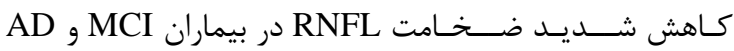

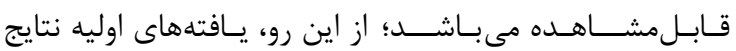

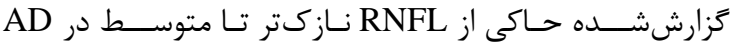

مىباشند [1].]

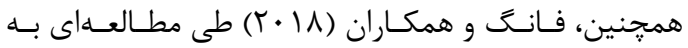

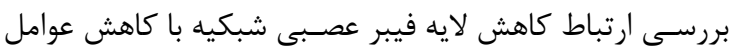

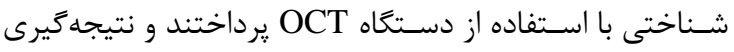

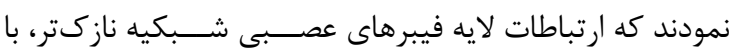
عملكرد بدتر شـناختى در افراد بدون بيمارى عصبى و همجنين

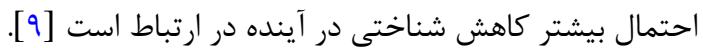

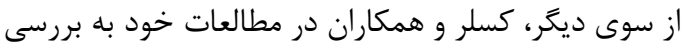

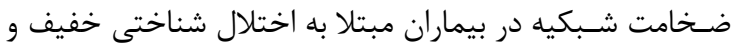

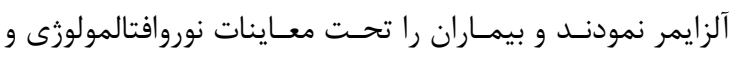

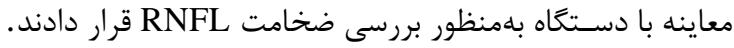

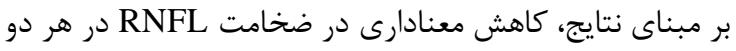

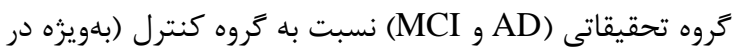

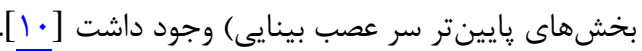

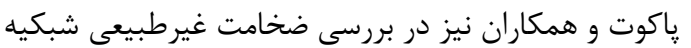

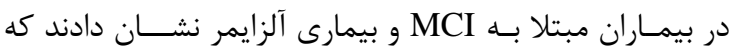

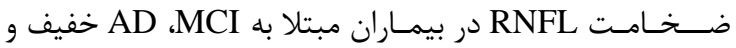
متوسـط تا شـديد نسـبت به كروه كنترل كاهش يافته است. به مبه

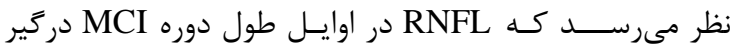

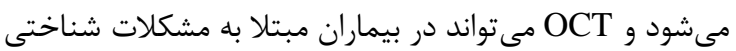
خفيف صورت بكيرد [11]

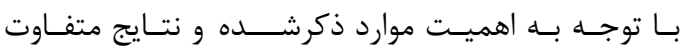
بهدسـتآمده، مطالعه حاضر با هدف تعيين ارتباط ضخامت لايه

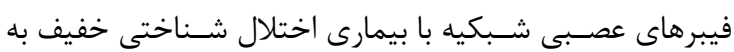
وسيله دستخاه OCT انجام شد.

\section{مواد و روشها}

مطالعه حاضـر به روش مورد- شاهدى در ارتباط با بيماران

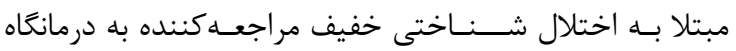

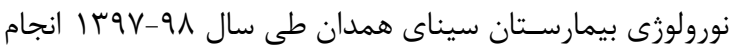
شده است.

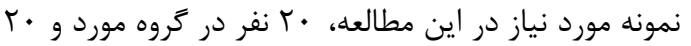

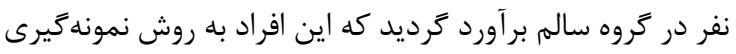

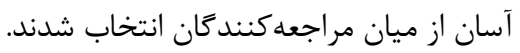

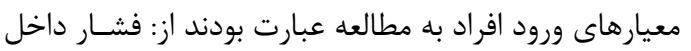

مىشـود، اطلاق مى گردد. اگر فردى به اختلال شناختى خفيف

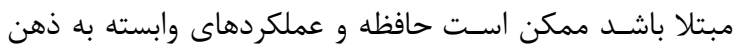

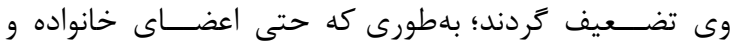

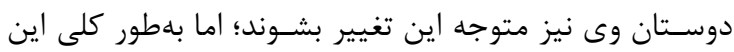

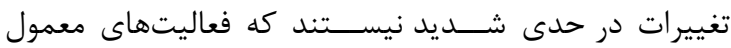

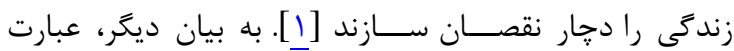

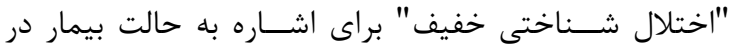

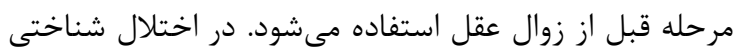

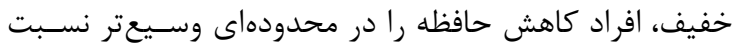

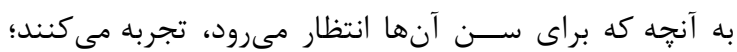

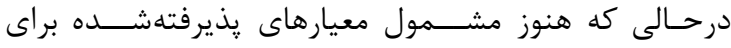

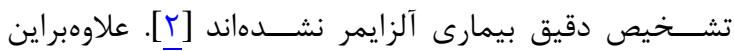

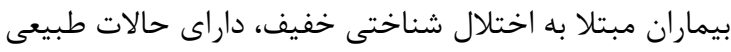

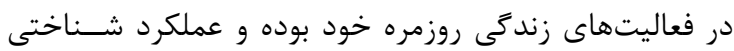

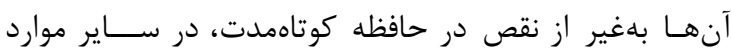
حالت طبيعى دارند [ب]. در مطالعات صـورت گرفته، كاهش ميدان بينايى و كوررنكى

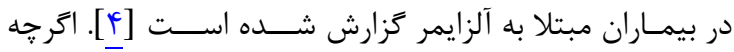
درگيرى مسيرهاى خلفى عصبى ممكن است بيشتر اين علائم را

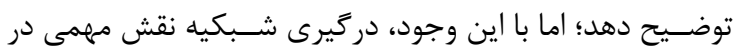

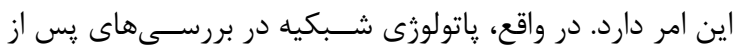

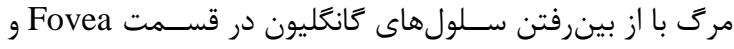
Para Fovea

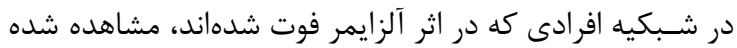

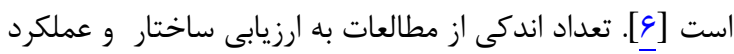

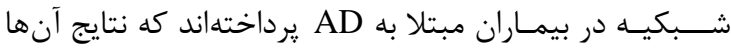

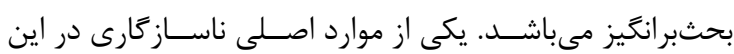

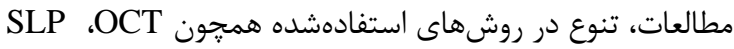
Heidelberg ) HRT , (Scanning Laser Polarimetry) Retina Tomography

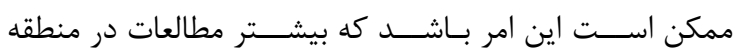

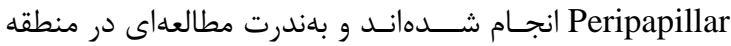

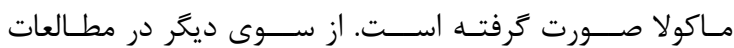
بافتشـناسـى، تغييرات عمدهاى در منطقه سـر عصب مشاهده

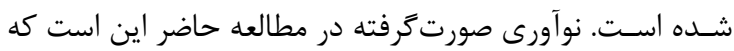

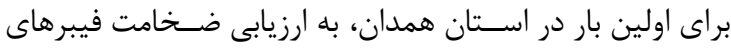

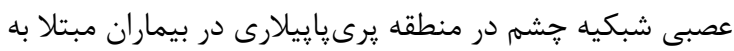

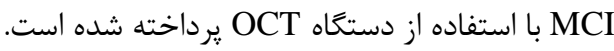

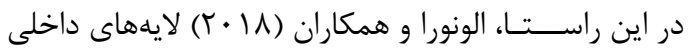

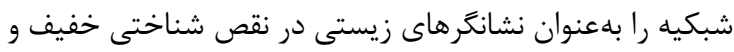

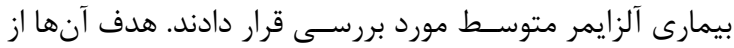

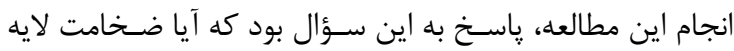

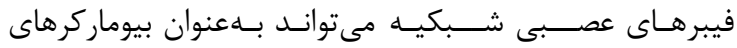

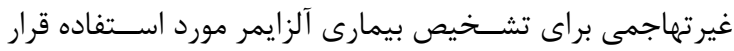


در يك اسليت لمب مناسب تعبيه شدهاند. لازم به ذكر است كه

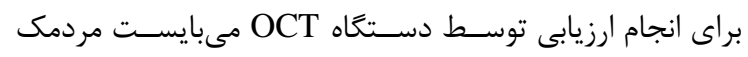
جشم كاملاً باز باشد (حداقل ه ميلى متر تونر).

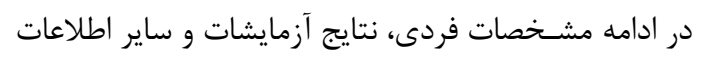

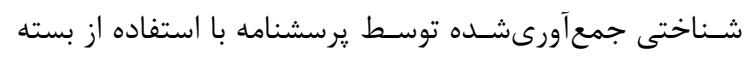

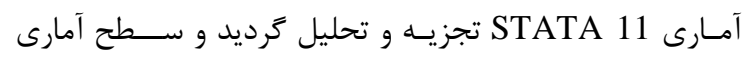
اهميت متغيرها معادل ينج درصد در نظر گرفته شد.

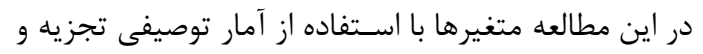

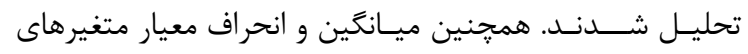

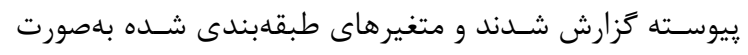

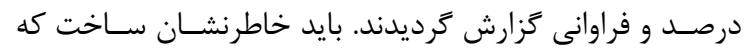

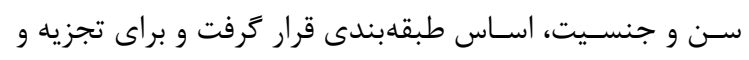

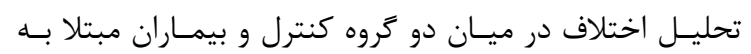

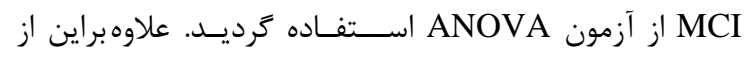

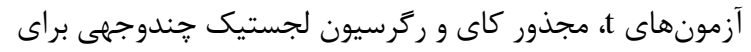

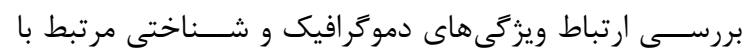

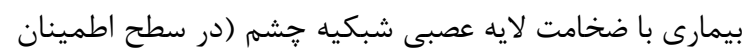
ه9 درصد) استفاده كرديد.

\section{يافته ها}

در اين مطالعه ·r بيمار مبتلا به اختلال شــناختى خفيف

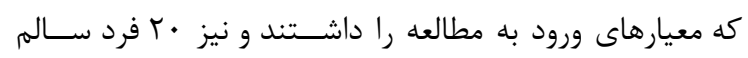

$$
\text { (كروه كنترل) مورد بررسى قرار كرفتند. }
$$

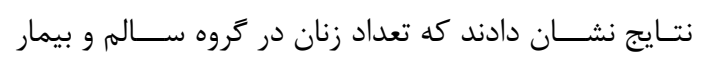

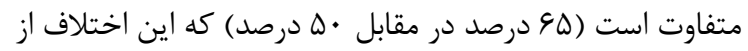

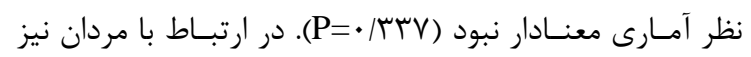

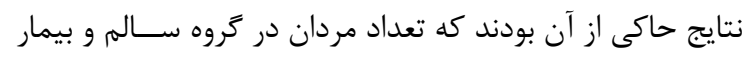

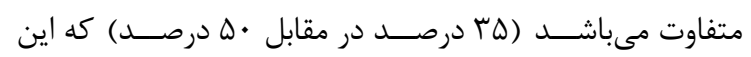

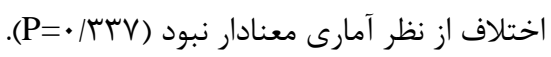

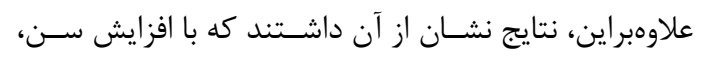

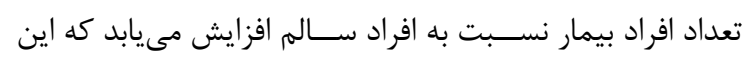

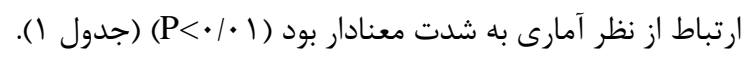

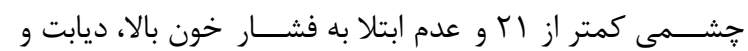

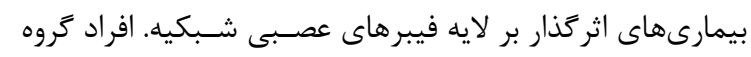
بيمار توسط متخصص مغز و اعصاب در كلينيك بيمارستان سينا

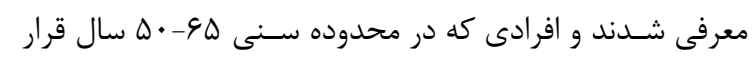

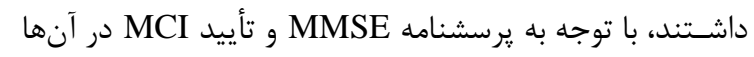

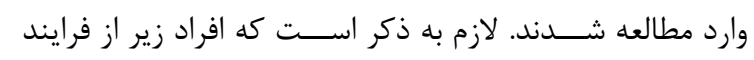

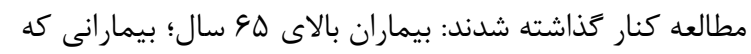

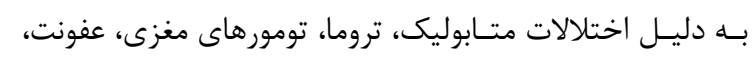

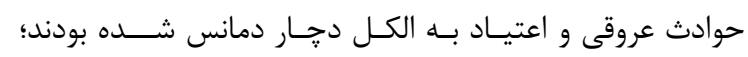

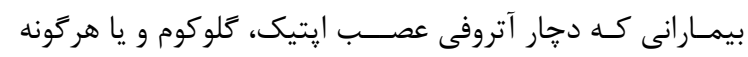
ضايعه عمده شبكيه بودند. افراد سـالم نيز از بين افرادى كه براى توديه تعيين شماره عينك

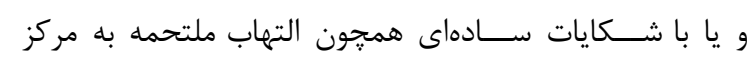

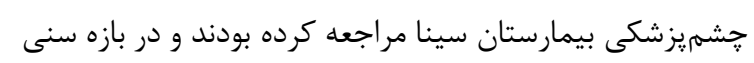
هو- •ه سال قرار داشتند، انتخاب شدند. در فرايند اجراى مطالعه، حدت بينايى در فاصـله و

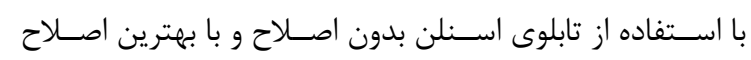
مشـخص كرديد. سيس بخش قدامى جشم شامل: قرنيه، عنبيه،

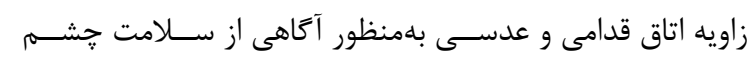
توسـط اسـليت لمب و روشهاى مختلف ديكر معاينه شد. فشار

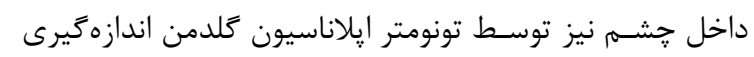

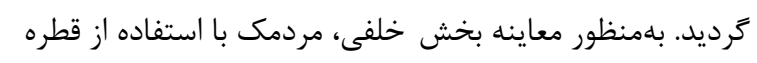

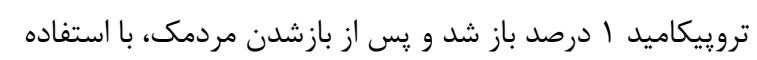

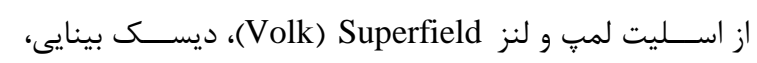

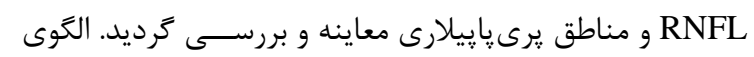

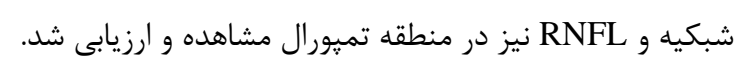
در مطالعه حاضر ارزيابى نهايى منطقه يرى ياييلارى شبكيه

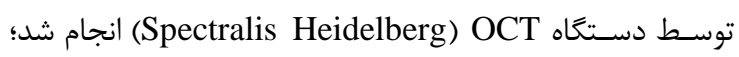

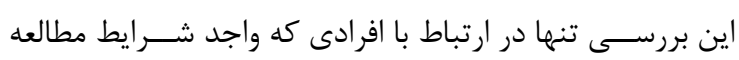

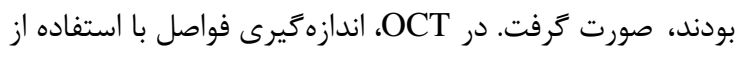

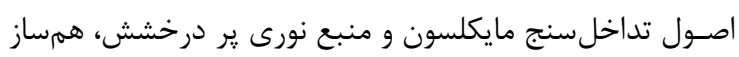

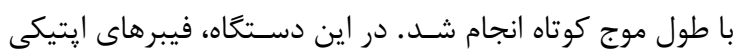

جدول ا: مقايسه متغيرهاى كيفى در افراد بيمار و سالم

\begin{tabular}{|c|c|c|c|c|c|c|}
\hline \multirow{2}{*}{ سطح معنادارى } & \multicolumn{2}{|c|}{ افراد بيمار } & \multicolumn{2}{|c|}{ افراد سالم } & & \multirow{2}{*}{ متغير } \\
\hline & درصد & تعداد & درصد & تعداد & & \\
\hline \multirow{3}{*}{ V V } & $\Delta \cdot$ & 1. & ra & V & مرد مرد & \multirow{3}{*}{ جنسيت } \\
\hline & $\Delta \cdot$ & 1. & $9 \Delta$ & Ir & زن & \\
\hline & $1 \ldots$ & $r$. & $1 \ldots$ & $r$. & كل & \\
\hline \multirow{3}{*}{-} & $\Delta$. & 1 . & - & - & $r-\Delta$ & \multirow{3}{*}{ طول مدت ابتلا (سال) } \\
\hline & 10 & r & - & - & $4-1$ & \\
\hline & ra & v & - & - & $9-11$ & \\
\hline \multirow{3}{*}{.$/ \cdot 1$} & $r$. & r & ra & v & $\Delta \cdot-\Delta \Delta$ & \multirow{3}{*}{ سن (سال) } \\
\hline & 1 . & r & ६. & it & $\Delta \varphi-q$. & \\
\hline & $\vee \cdot$ & If & $\Delta$ & 1 & $91-90$ & \\
\hline
\end{tabular}


راسـت بود و در ربعهاى تميورال و نازال در جشم راست، كمى

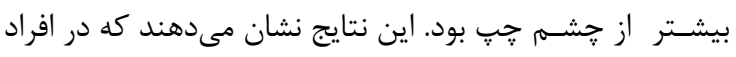

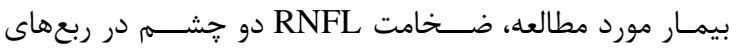

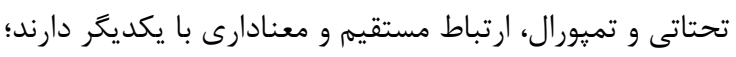

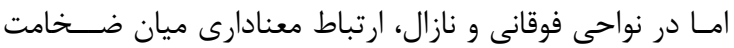
RNFL

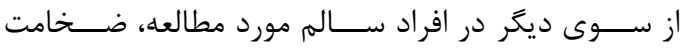

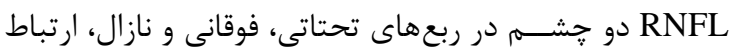

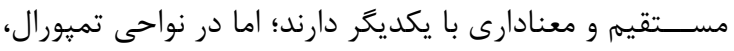

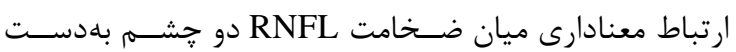
نيامد.

در جدول r شــاخصهاى مركزى و يراكند RNFL به تفكيك ربع هاى مختلف شــبكيه در دو گروه بيماران

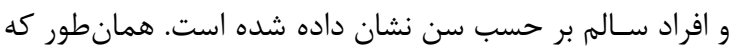

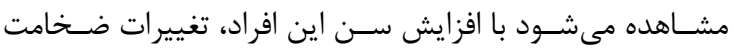

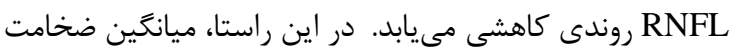

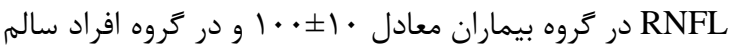

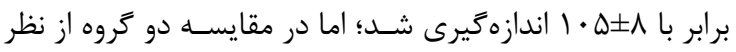

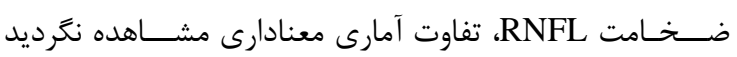

$(\mathrm{P}>\cdot / \cdot \Delta)$

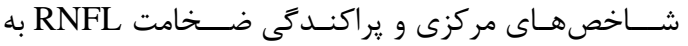

تفكيك ربع هاى مختلف شبكيه در بيماران بر حسب طول مدت مدر هري

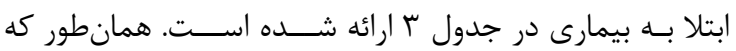

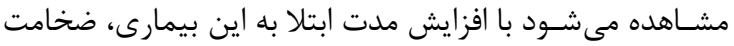

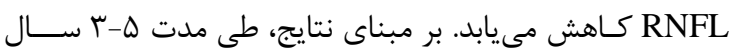

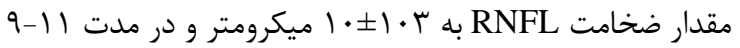
سال به • مجد9 ميكرومتر كاهش يافته است.
بر مبناى نتايج ميانكين نمره MMSE برابر با آى، حداقل

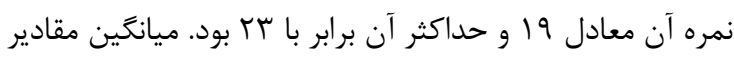

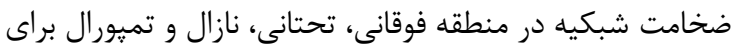

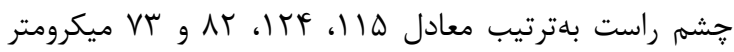
بهدست آمد. ميانكين مقادير ضخامت شبكيه در منطقه فوقانى،

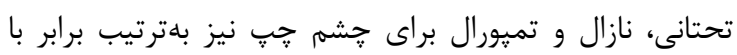
F

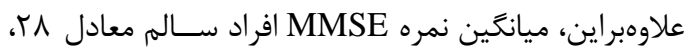

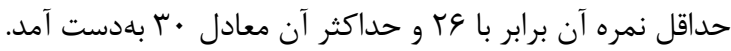

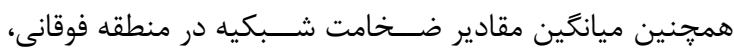

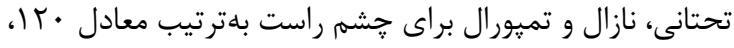

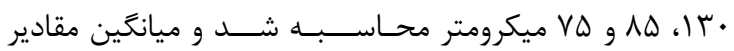

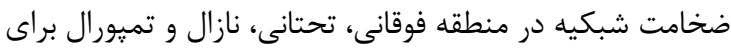

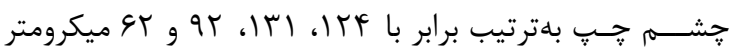

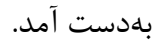

همـانطور كـه در شـــــل 1 ملاحظــه مى شــــود، در تمام

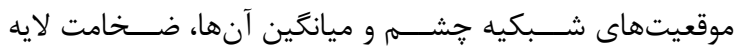
فيبرهاى عصبى شبكيه در افراد بيمار اندكى كمتر از افراد سالم

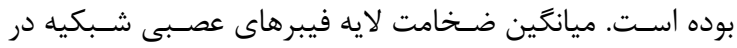

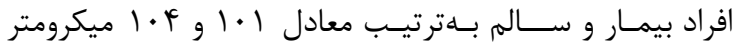
محاسبه گر ديد.

مقايسـه ضـخامت RNFL در ربعهاى همنام دو جشــم در زنان و مردان نشـان مىدهد كه ضخامت مشابهى دارند (تفاوت

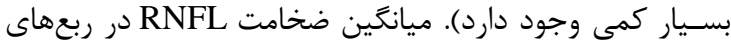

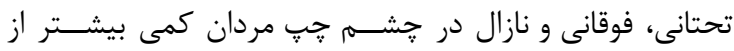

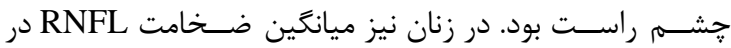

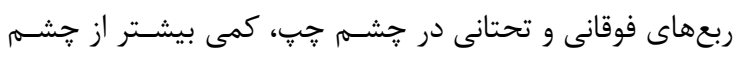

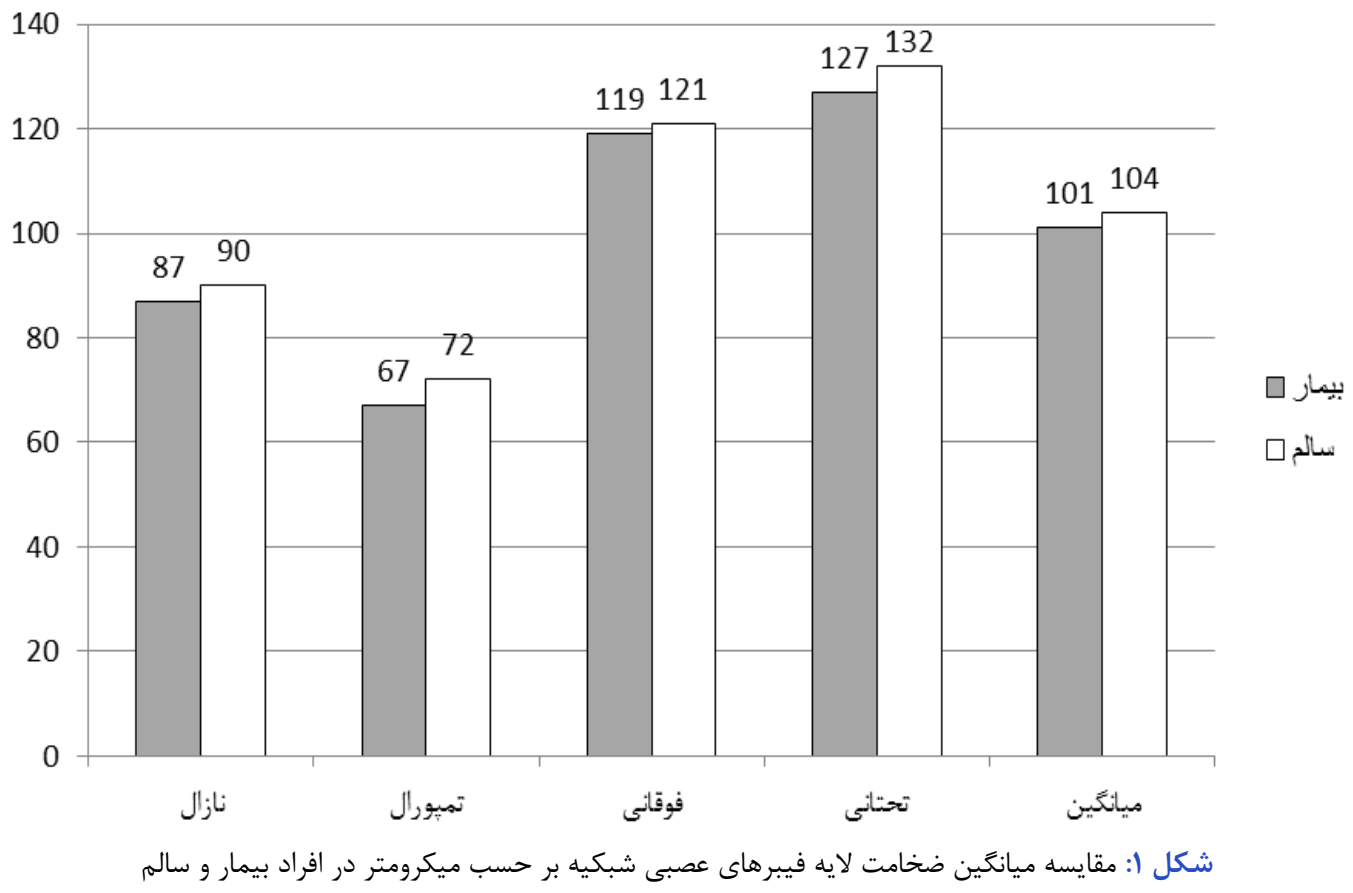


جدول ب: شاخصهاى مركزى و يراكندگى ضخامت RNFL بر حسب ميكرومتر به تفكيك ربعهاى مختلف شبكيه در بيماران و افراد سالم

\begin{tabular}{|c|c|c|c|c|c|c|}
\hline جمع & ميانغين土|نحراف معيار & ميانَين土|نحراف معيار & 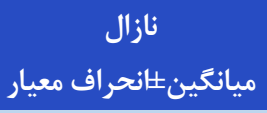 & 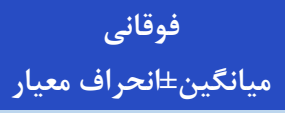 & سن & كروه \\
\hline & & & & & & بيماران \\
\hline$\wedge \pm 1 \cdot \wedge$ & $\Delta \pm V Y$ & $19 \pm 1 \mathrm{Fr}$ & $19 \pm 19$ & $1 \Delta \pm \| r$. & $\Delta \cdot-\Delta \omega$ & \\
\hline $19 \pm 1 \cdot V$ & $|f \pm 9|$ & $r \Delta \pm I f r$ & $\wedge \pm q$. & $|\wedge \pm \|| V$ & $\Delta s-\varepsilon$. & \\
\hline $9 \pm 91$ & $1 \cdot \pm 99$ & IDEITT & $\| \boldsymbol{Y} \pm \wedge V$ & $1 \cdot \pm 11 \mathrm{~V}$ & $91-90$ & \\
\hline $1 \cdot \pm 1 \ldots$ & $1 \cdot \pm 9 \wedge$ & $1 \Lambda \pm 1 Y q$ & $\| f \pm \Lambda V$ & $1 r \pm 119$ & جمع & \\
\hline & & & & & \multicolumn{2}{|c|}{ افراد سالم } \\
\hline $1 \cdot \pm 1 \cdot 9$ & $9 \pm V I$ & $|V \pm| r G$ & $r I \pm \Lambda \Lambda$ & $\| \Psi T$ & $\Delta \cdot-\Delta \Delta$ & \\
\hline$V \pm 1 \cdot r$ & $V \pm V F$ & $|f \pm| r$. & $|r \pm q|$ & $11 \pm 1 Y Y$ & $\Delta \varphi-\varepsilon$. & \\
\hline$\cdot \pm 1 \cdot r$ & $\cdot \pm 9 \Lambda$ & $\cdot \pm 1 r \Lambda$ & $\cdot \pm 99$ & $\cdot \pm 11 \cdot$ & $91-90$ & \\
\hline$\Lambda \pm 1 \cdot \Delta$ & $4 \pm V r$ & $1 \Delta \pm I r T$ & $10 \pm 9$. & r & جمع & \\
\hline
\end{tabular}

جدول س: شاخصهاى مركزى و ثراكندگى ضخامت RNFL بر حسب ميكرومتر به تفكيك ربع هاى مختلف شبكيه در بيماران بر حسب طول مدت ابتلا به بيمارى

\begin{tabular}{|c|c|c|c|c|c|}
\hline جمع & ميانغين土|نحراف معيار & ميانكين土|نحراف معيار & ميانتين+انحراف معيار & 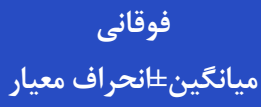 & مدت بيمارى (سال) \\
\hline $1 \cdot \pm 1 \cdot r$ & $4 \pm V r$ & $r \mid \pm I r F$ & $\mid r \pm \Lambda r$ & $I F \pm I T Y$ & $r-\omega$ \\
\hline$\wedge \pm 1 \cdots / \vee$ & $\Delta \pm q \Lambda$ & $r \pm \| 1 \Lambda$ & $r \cdot \pm 9 \Delta$ & $\Delta \pm|r|$ & $9-1$ \\
\hline $1 \cdot \pm 99$ & $\mid r \pm q T$ & $|V \pm| r G$ & $|r \pm q|$ & $11 \pm 111$ & $9-11$ \\
\hline $1 \cdot \pm 1 \cdots$ & $1 \cdot \pm 9 \wedge$ & $1 \wedge \pm 1 r q$ & $\| f \pm \Lambda V$ & $1 r \pm 119$ & جمع \\
\hline
\end{tabular}

يافته با نتايج مطالعه بادنز و همكاران همراستا مىباشد [1 ا1].].

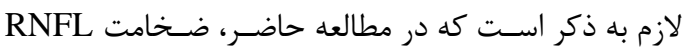

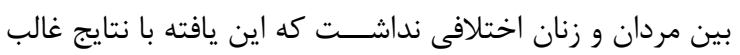

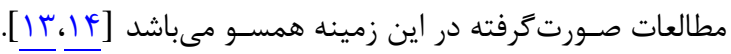

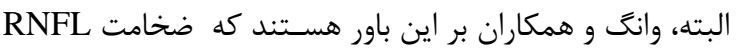

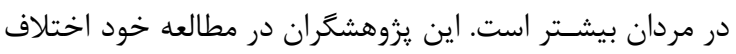

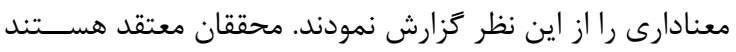

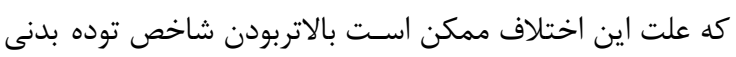
مردان در مقايسه با زنان باشد.

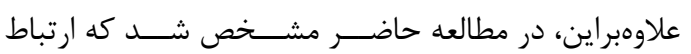

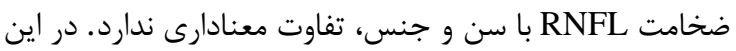

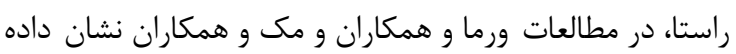

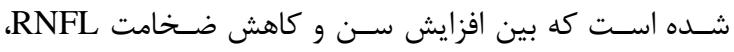

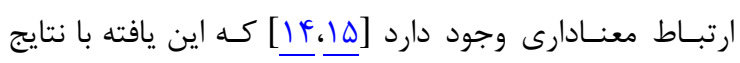
مطالعه حاضر مغاير مىباشد.

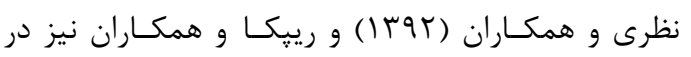
مطالعات خود كاهش ضــخامت وابســته به ســـن را در در لايه

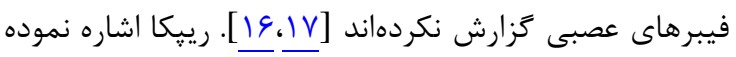

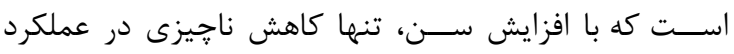

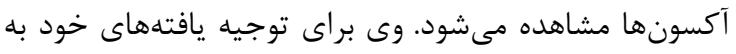

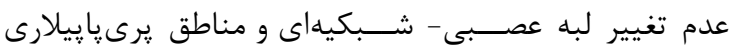

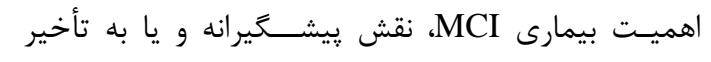

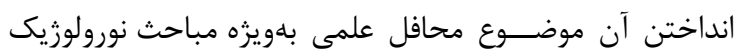

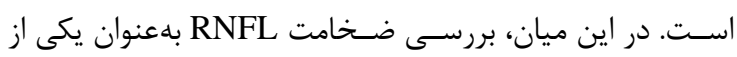

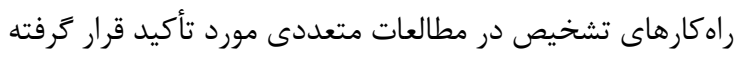

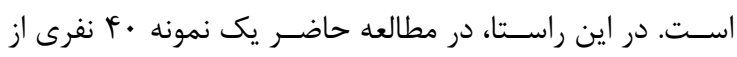

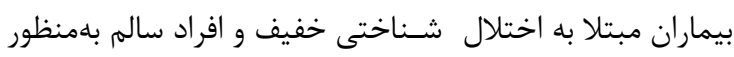

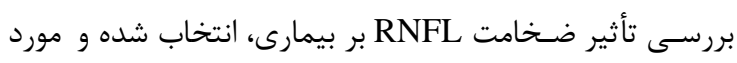

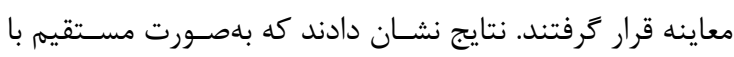

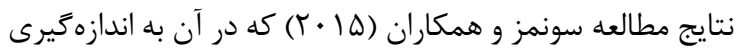

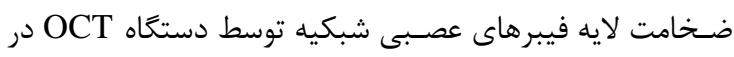

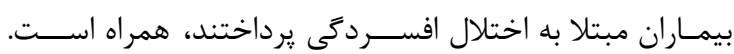

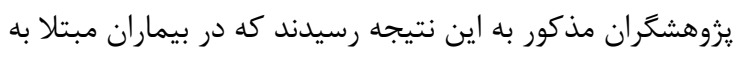

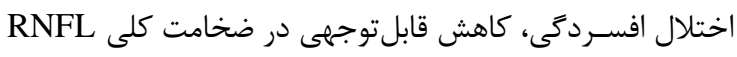

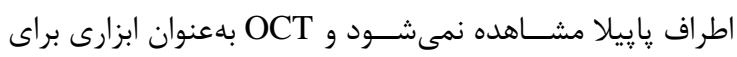

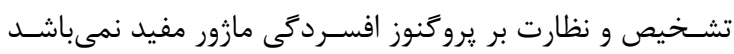

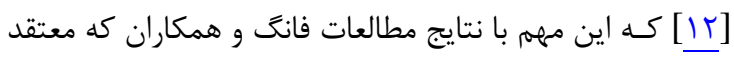
هستند ارتباطات لايه فيبر عصبى شبكيه نازكىتر با عملكرد بدتر

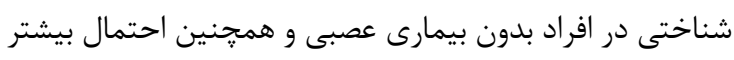

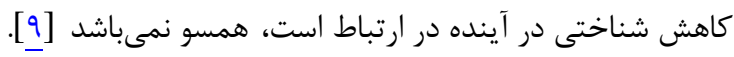

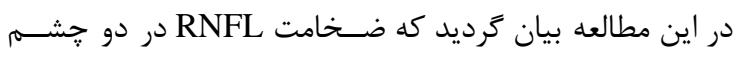

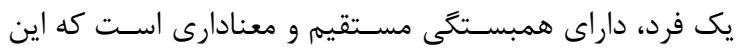




$$
\begin{aligned}
& \text { مىباشــد. بدينوســـله نويســـــــان مراتب قدردانى خود را از } \\
& \text { معـاونـت تحقيقـات و فنــاورى دانشــــــاه و تمـامى بيمـاران } \\
& \text { شركت كننده در مطالعه اعلام مىنمايند. }
\end{aligned}
$$

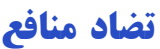

نتايج اين مطالعه با منافع نويسندكان در تعارض نمىباشد.

\section{ملاحظات اخلاقي}

از تمامى افراد شركت كننده، رضايتنامه آكاهانه شركت در

مطالعه اخذ شد و روش تحقيق به تأييد كميته اخلاق دانشعاه

علوم يزشكى همدان (با كد

$$
\begin{aligned}
& \text { سمهم ذو يسنلفكان }
\end{aligned}
$$

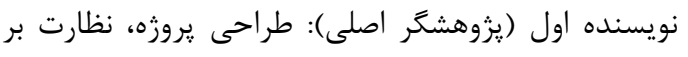

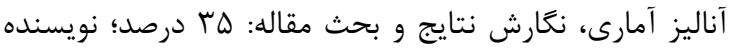

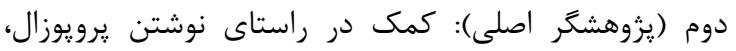

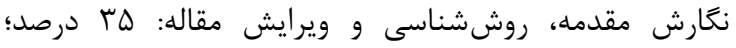

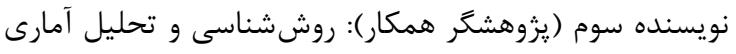

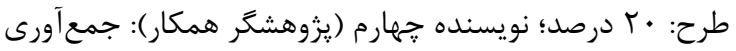

$$
\begin{aligned}
& \text { نمونهها: • (1 درصد. } \\
& \text { علوم يزشكى همدان يشتيبانى مالى شده است. }
\end{aligned}
$$

\section{حمايت مالكى}

\section{REFERENCES}

1. Alzheimer's Association. Help fight Alzheimer's. Chicago: Alzheimer's Association; 2018.

2. Ankri J, Poupard M. Prevalence and incidence of dementia in the very elderly. Review of the literature. Rev Epidemiol Sante Publique. 2003;51(3):349-60.

3. Yokeş MB. Molecular genetics of Alzheimer's disease. J Cell Mol Biol. 2007;6(2):73-97.

4. Cogan DG. Visual disturbances with focal progressive dementing disease. Am J Ophthalmol. 1985;100(1):68-72. PMID: 3893141 DOI: 10.1016/s0002-9394(14)74985-2

5. Cronin-Golomb A, Corkin S, Growdon JH. Visual dysfunction predicts cognitive deficits in Alzheimer's disease. Optom Vis Sci. 1995;72(3):168-76. PMID: 7609939 DOI: 10.1097/00006324-199503000-00004

6. Cummings JL. Cognitive and behavioral heterogeneity in Alzheimer's disease: seeking the neurological basis. Response to commentaries. Neurobiol Aging. 2000; 21(6):845-61. DOI: 10.1016/S0197-4580(00)00183-4

7. Danesh-Meyer HV, Birch H, Ku JY, Carroll S, Gamble G. Reduction of optic nerve fibers in patients with Alzheimer disease identified by laser imaging. Neurology. 2006; 67(10):1852-4. PMID: 17130422 DOI: 10.1212/01.wnl. $0000244490.07925 .8 \mathrm{~b}$

8. Lad EM, Mukherjee D, Stinnett SS, Cousins SW, Potter GG, Burke JR, et al. Evaluation of inner retinal layers as biomarkers in mild cognitive impairment to moderate Alzheimer's disease. PLoS One. 2018;13(2):e0192646. PMID: 29420642 DOI: 10.1371/journal.pone.0192646

9. Ko F, Muthy ZA, Gallacher J, Sudlow C, Rees G, Yang Q, et
اسـتناد نموده اسـت. علتى كه مىتوان براى توضـيح تفاوت

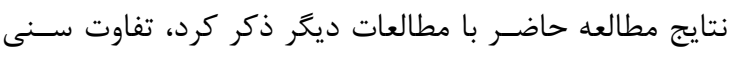

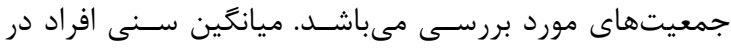

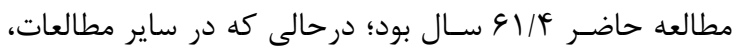

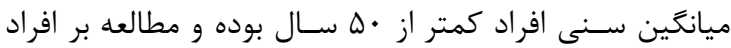

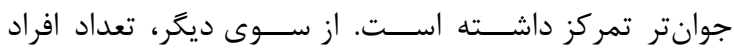

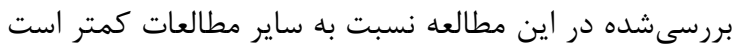

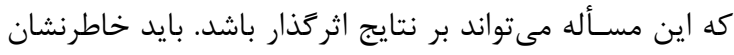

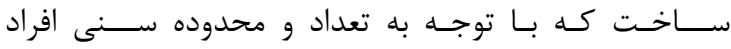

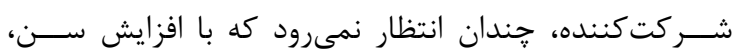
ضخامت RNFL تغيير نمايد.

\section{نتيجه كيرى}

در مجموع، آنجه از مطالعه حاضر برمى آيد اين است كه به

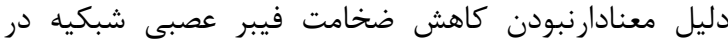

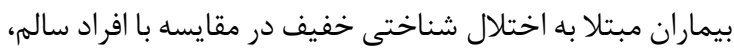

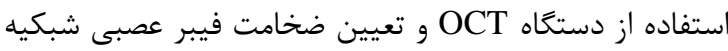

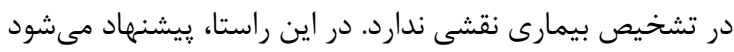

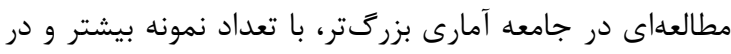

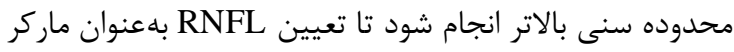
تشخيصى بيمارى اختلال شناختى خفيف، با دقت بالام بالاترى

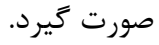

\section{تشكر و قلرواذى}

مقاله حاضــر بركرفته از يايان نامه دكترى حرفهاى يزشـكى

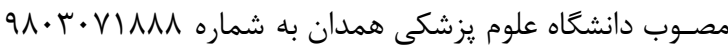

al. Association of retinal nerve fiber layer thinning with current and future cognitive declinea: a study using optical coherence tomography. JAMA Neurol. 2018;75(10):1198205. PMID: 29946685 DOI: $10.1001 /$ jamaneurol.2018.1578

10. Kesler A, Vakhapova V, Korczyn AD, Naftalive E, Neudorfer M. Retinal thickness in patients with mild cognitive impairment and Alzheimer's disease. Clin Neurol Neurosurg. 2011;113(7):523-6. PMID: 21454010 DOI: 10.1016/j.clineuro.2011.02.014

11. Paquet C, Boissonnot M, Roger F, Dighiero P, Gil R, Hugon J. Abnormal retinal thickness in patients with mild cognitive impairment and Alzheimer's disease. Neurosci Lett. 2007; 420(2):97-9. PMID: 17543991 DOI: 10.1016/j.neulet. 2007.02.090

12. Sonmez I, Kosger F, Aykan U. Retinal nerve fiber layer thickness measurement by spectral-domain optical coherence tomography in patients with major depressive disorder. Noro Psikiyatr Ars. 2017;54(1):62-6. PMID: 28566961 DOI: 10.5152/npa.2015.10115

13. Budenz DL, Anderson DR, Varma R, Schuman J, Cantor L, Savell J, et al. Determinants of normal retinal nerve fiber layer thickness measured by Stratus OCT. Ophthalmology. 2007;114(6):1046-52. PMID: 17210181 DOI: 10.1016/j. ophtha.2006.08.046

14. Varma R, Bazzaz S, Lai M. Optical tomography-measured retinal nerve fiber layer thickness in normal Latinos. Invest Ophthalmol Vis Sci. 2003;44(8):3369-73. PMID: 12882783 DOI: 10.1167/iovs.02-0975

15. Mok KH, Lee VW, So KF. Retinal nerve fiber layer 
measurment of the Hong Kong Chinness population by optical coherence tomography. J Glaucoma. 2002;11(6):481-3.

16. Nazari M, Baladi MN, Entezari M. Comparison of the thickness of the retinal nerve fibers in normal people with multiple sclerosis patients with optic neuritis. [PhD Thesis]. Tehran: Medical School, Shahid Beheshti University of
Medical Sciences and Health Services; 2013. [Persian]

17. Repka AX, Quigly HA. The effect of age on normal human optic nerve fiber layer number and diameter. Ophthalmology. 1989;96(1):26-32. PMID: 2919049 DOI: 10.1016/s0161$\underline{6420(89) 32928-9}$ 